\title{
Recent Trends in Industrial Biotechnology
}

\author{
Saif $\mathbf{S}^{1 *}$, Mazhar MW', Sikandar $\mathbf{M}^{1}$, Waqas $\mathbf{N}^{1}$ and \\ Ijaz $\mathbf{A}^{2}$ \\ ${ }^{1}$ Department of Bioinformatics and Biotechnology, \\ Government Collage University, Faisalabad, Pakistan \\ ${ }^{2}$ National Center of Excellence in Molecular Biology, \\ University of Punjab Lahore, Pakistan \\ *Correspondling author: Saira Saif, Department of \\ Bioinformatics and Biotechnology, Government Collage \\ University, 38000 Faisalabad, Pakistan
}

Received: May 11, 2021; Accepted: J une 02, 2021;

Published: J une 09, 2021

\section{Introduction}

White biotechnology, also known as, industrial biotechnology has been skyrocketing in commercial markets because of the production of useful industrial products by using microorganisms. Today, microorganisms are being used for the production of commercially useful products, such as biofuels, pulp and paper, food, textile and detergents. To diversify the economical values, industrial biotechnology is making use of "genetically modified organisms" to enhance the efficiency of products [1]. Industrial biotechnology focuses on the production of the following products (Figure 1).

\section{Biofuel production}

Biofuel production focuses on limiting greenhouse gas emission to prevent global warming, and making the environment clean of any pollution. Ethanol fuel is the most commonly used biofuel, produced by the fermentation of ethanol. Ethanol is produced by the yeast fermentation of cassava, potato, corn, and sugarcane. The production of biofuels is of economic value in agriculture sectors, thus promoting agriculture development in both rural and urban areas.

Biofuels has taken over the industrial biotechnology agenda in recent years. The year 2005 has been regarded as the peak point for biofuels.

\section{Categories of bio fuels:}

There are some categories of Biofuels which are as follows:

Renewable fuels: Renewable fuels refer to bioethanol and bio butanol derived from corn starch; the vast majority of bioethanol from corn starch are generally called as First generation bioethanol.

Biomass-based diesel: It refers to the production of both biodiesel and renewable diesel from soy oil or waste oil, fats, greases as well as biodiesel and renewable diesel is also being produced from algal oils.

Advance biofuels: It accommodates ethanol from sugarcane. It complies with 50 percent greenhouse gas reduction threshold for advanced biofuels.

Cellulose biofuels: It refers to the cellulosic ethanol and cellulosic diesel. It is also called as second generation ethanol.

\section{Production of fermented foods}

Ancient civilizations have been making food, such as idli, dosa, wine, breads, curds, and cheese by the fermentation process. Industrial fermentation focuses on providing useful products to humans by the use of microorganisms like fungi, yeast, and bacteria to make fermented food products. The fermentation process is highly reliant of the temperature, $\mathrm{PH}$, concentration of microbes to be used, enzymes, and oxygen (for aerobic fermentation). Genetically Modified Microorganisms (GMOs) have been used in the production of several enzymes, such as rennet, invertase, amylases, and lipases, etc [2].

\section{Production of pharmaceuticals}

Amino acids are of main concern for the production of pharmaceuticals and secondary compounds, including flavor enhancers, and food additives. E. coli and Lactobacillus species are some of the best bioreactor systems to use pharmaceutical products [3].

\section{Role of Enzymes at Industrial Scale}

Industrial enzymes find their applications in food industry to make fermented foods and improve their taste and texture. Bacterial and fungal enzymes are widely used in fermentation processes because they are a preferred source than animal and plants enzymes due to their cost-efficiency and stability. Here are some of the examples of enzymes that are extensively used in food sectors:

\section{$\alpha$ - amylases}

Alpha amylases because of their integrity and stability are dextrins, powdery foods, glucose syrups, and rice cakes. They are also used in the baking industry to improve bread quality, enhance flavor, and improve crust color, taste, and toast quality of the breads. These are starch degrading enzymes capable of hydrolyzing a $\alpha-1,4$ glyosidic bond of polysaccharides which result in the production of short chain dextrin. These enzymes play an important role in the food industry including baking, brewing, starch liquefaction as well as digestive aid. They are used as glazing agents for the production of rice cakes.

\section{Lipases}

Lipases are used to process fat-containing foods and enhance the flavor in dairy products. Lipases produce free fatty acids by acting on the milk fats to improve cheese flavor. Lipases are used to produce different type of cheese, such as cheddar cheese, camembert cheese, and Romano cheese. They also improve the quality and overall texture of different types of cheese. From improving quality of cocoa butter to developing alcoholic wine beverages, lipases are widely used in food industry $[4,5]$.

\section{Fungal Laccases}

Fungal laccases find their applications in many areas of industrial biotechnology, including lignin degradation, morphogenesis, and biosynthesis. They also act as biocatalysts and initiate the chemical reactions. Fungal laccases are used in the stability of food products, production of anti-oxidant hormonal drugs and anti-cancerous drugs, and in other sectors for the preparation of immunological 
Table 1: Characteristics of Nano Techniques.

\begin{tabular}{|l|l|l|l|}
\hline $\begin{array}{c}\text { Nano } \\
\text { techniques }\end{array}$ & \multicolumn{1}{|c|}{ Characteristics features } & References \\
\hline Edible coatings & To preserve the quality of fresh food during extended storage. & $\begin{array}{l}\text { Gelatine based edible coatings containing cellulose nanocrystal. } \\
\text { Chitosan film with nano SiO }{ }_{2} .\end{array}$ \\
\hline $\begin{array}{l}\text { Polymeric } \\
\text { micelles }\end{array}$ & $\begin{array}{l}\text { Solubilize water -insoluble compounds in the hydrophobic interior, } \\
\text { high solubility, low toxicity. }\end{array}$ & $\begin{array}{l}\text { PEO-b-PCL (poly ethylene glycol) block (poly caprolactone) Beta } \\
\text { carotene based nano emulsion. }\end{array}$ \\
\hline $\begin{array}{l}\text { Liposomes } \\
\text { It can be used as delivery vehicles for hydrophobic molecules or } \\
\text { hydrophilic molecules. }\end{array}$ & Cationic lipid incorporated liposomes modified with an \\
\hline $\begin{array}{l}\text { Nano } \\
\text { emulsions }\end{array}$ & Higher optical clarity and increased bioavailability. & Beta carotene based nano emulsion \\
\hline
\end{tabular}

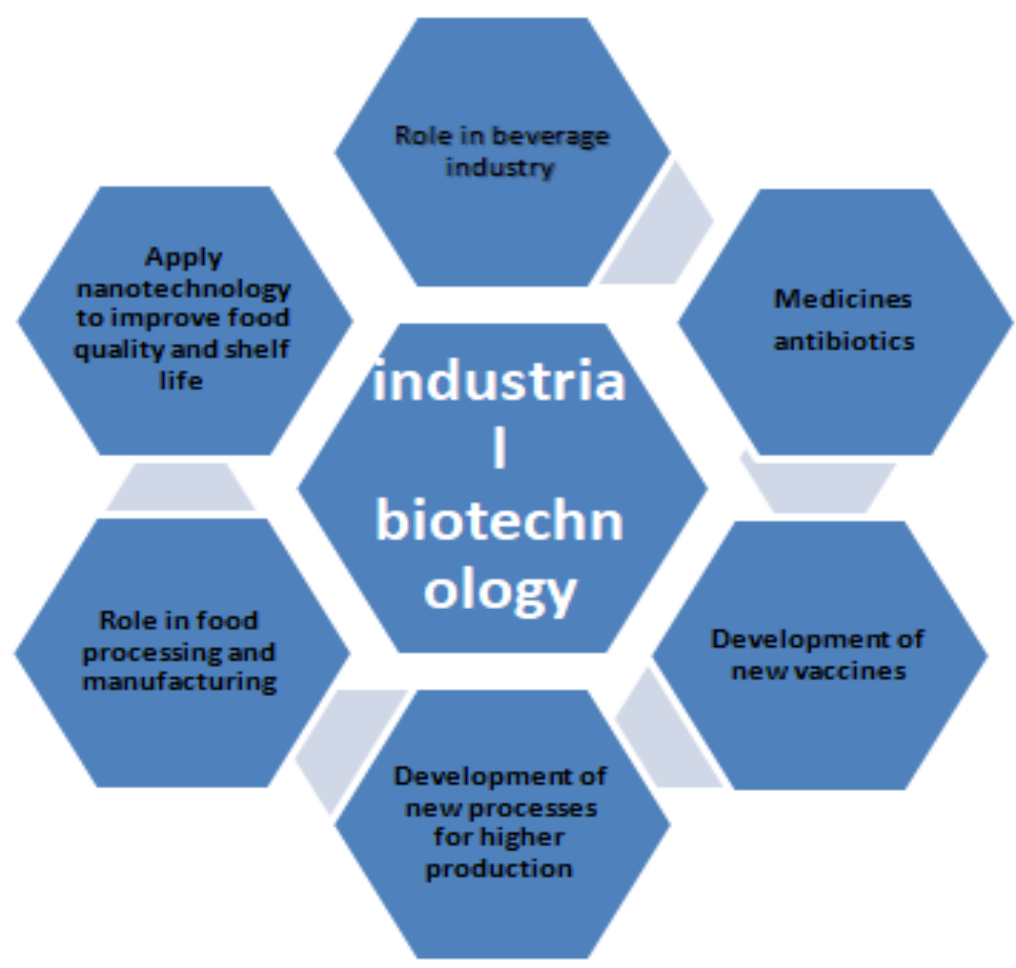

Figure 1: Industrial Biotechnology.

assays, biosensors, and DNA labeling [6].

\section{Pectinases}

Natural microbes, as well as recombinant microbes produce pectinase enzyme (endopeptidases and exopeptidases). At the industrial level, pectinases are used in the food industry, remediation, and paper bleaching. To improve the flavor and color of juices, pectinases reduce the turgidity in naturally derived fruit juices like apples and bananas [7].

\section{Glucoamylases}

Hydrolysis of Polysaccharide starch from the non-reducing agents is done with the help of glucoamylase, releasing the B-glucose. These are also called as scarifying enzymes. At industrial level they are used for the production of glucose syrup and fructose syrup Glucoamylases coverts the starch present in flour into maltose and fermented sugars.

\section{Lactase (B-Galactosidase)}

This enzyme is responsible for the hydrolysis of lactose in milk of whey. Lactase is used with milk and milk-based products to reduce the lactose intolerance in people. Lactase also increased the smoothness and creaminess of ice-cream at industrial level.

\section{Role of Nanotechnology at Industrial Scale}

Nanotechnology has emerged as a sustainable field showing its efficient benefits in almost every sector of biotechnology, most importantly in medicine and industrial sectors. Nanotechnology uses Nano materials, which contribute to high-quality, safer, nonperishable, and healthier foods. Packaging food products, monitoring the quality of packaged food, and smart food packaging are some of the advantages of Nano sensors. In the food industry, nanotechnology is used to extend the shelf life of food products, detect food borne pathogens, food packaging, and food processing (Table 1).

\section{Nanotechnology for improving food quality}

Nanotechnology has introduced a technique, called Nano encapsulation, to improve the overall quality, texture, and flavor of the food. Nano encapsulated particles improve the bioavailability of nutraceuticals compounds. Nowadays, $\mathrm{SiO}_{2}$ nanomaterials have become popular in the food industry to add flavors and fragrances in food products. 


\section{Nutritional value}

Highly acidic stomach environment of humans makes biomolecules, such as vitamins, carbohydrates, and protein to be more sensitive to digest. Nano encapsulation technique not only makes these biomolecules resistant to adverse environments, but also makes them easily soluble in water. Nanoparticles add nutritional values to food products by allowing the biomolecules to assimilate in food products easily [8].

\section{Shelf life}

The shelf life of a food product is greatly reduced because of the degradation and inactivation of bioactive compounds. Now, the degradation process can easily be slowed down by nanoncapsulation, which aims for extending the shelf life of packaged foods. Nano encapsulation also facilitates an extension in the shelf life of manufactured foods even their packaging is open.

\section{References}

1. Johnson FX and C Linke-Heep. Industrial biotechnology and biomass utilisation. Futur. Prospect. Ind. Biotechnol. 2008.

2. Demain $\mathrm{AL}$ and $\mathrm{JL}$ Adrio. Contributions of Microorganisms to Industrial Biology. Molecular Biotechnology. 2007; 38: 41-55.

3. Ivanov K, et al. Biotechnology in the Production of Pharmaceutical Industry Ingredients: Amino Acids. Biotechnology \& Biotechnological Equipment. 2013; $27:$ 3620-3626
4. Guerrand D. Lipases industrial applications: focus on food and agroindustries. OCL Oilseeds and fats crops and lipids. 2017; 24: D403.

5. Guerrand D. Lipases industrial applications: Focus on food and agroindustries OCL. 2017; 24: D403.

6. Senthivelan T, J Kanagaraj and RC Panda. Recent trends in fungal laccase for various industrial applications: An eco-friendly approach - A review. Biotechnology and Bioprocess Engineering. 2016; 21: 19-38.

7. Pedrolli DB, et al. Pectin and pectinases: production, characterization and industrial application of microbial pectinolytic enzymes. Open Biotechnology Journal. 2009: 9-18.

8. Singh T, et al. Application of nanotechnology in food science: perception and overview. Frontiers in microbiology. 2017; 8: 1501.

9. Ravichandran R. Nanotechnology applications in food and food processing innovative green approaches, opportunities and uncertainties for global market. International Journal of Green Nanotechnology: Physics and Chemistry. 2010; 1: P72-P96.

10. Trujillo LE, et al. Nanotechnology applications for food and bioprocessing industries. Biology and Medicine. 2016; 8: 1.

11. Singh $\mathrm{H}$. Nanotechnology applications in functional foods; opportunities and challenges. Preventive nutrition and food science. 2016; 21: 1-8.

12. Thiruvengadam M. G Rajakumar and I-M Chung. Nanotechnology: current uses and future applications in the food industry. 3 Biotech. 2018; 8: 1-13. 